\title{
IMPLEMENTASI MONITORING DAN EVALUASI INTERNAL (MONEVIN) PADA ROGRAM HIBAH (Studi Kasus Pada PHK PKPD Universitas Islam Indonesia)
}

\author{
Tatik \\ Program D3 FE Universitas Islam Indonesia \\ tatikpawiro@gmail.com
}

\begin{abstract}
This study aims to determine the implementation of monitoring and evaluation (internal evaluation and evaluation) which functions as an internal audit of grant programs at the Indonesian Islamic University. The study used qualitative methods with a case study approach. Researchers chose the research location at the Indonesian Islamic University because the university had the best performance as the recipient of the best performance PKPD PHK Grant Program for the 2011-2014 period for the category of Private Higher Education / State-Owned Legal Entities. The data used is primary data. Data is obtained from documents, archive records, interviews and participant observation. Informants / speakers come from various parties who are competent to provide the information needed. This research uses credibility testing methods by extending observation, triangulation and membership. The results of this study indicate that internal monitoring and evaluation can be effective if supported by employee competencies, compensation and work culture that are built on the values of Islam that are believed.
\end{abstract}

Keywords: implementation, monevin, grant program, Islam

\begin{abstract}
Abstrak
Penelitian ini bertujuan untuk mengetahui implementasi monevin (montoring dan evaluasi internal) yang berfungsi sebagai audit internal program hibah pada Universitas Islam Indonesia. Penelitian menggunakan metode kualitatif dengan pendekatan studi kasus. Peneliti memilih lokasi penelitian di Universitas Islam Indonesia karena universitas tersebut memiliki prestasi sebagai penerima hibah PHK PKPD (Program Hibah Kompetisi Peningkatan Kualitas Pendidikan Dokter) dengan kinerja terbaik periode 2011-2014 untuk kategori Perguruan Tinggi Swasta/BHMN (Badan Hukum Milik Negara). Data yang digunakan adalah data primer. Data diperoleh dari dokumen, rekaman arsip, wawancara dan observasi partisipan. Informan/narasumber berasal dari berbagai pihak yang kompeten memberikan informasi yang diperlukan. Penelitian ini menggunakan metode pengujian kredibilitas dengan cara perpanjangan pengamatan, triangulasi dan memberchek. Hasil penelitian ini menunjukkan bahwa monitoring dan evaluasi internal dapat berjalan efektif jika didukung oleh kompetensi pegawai, kompensasi dan budaya kerja yang dibangun dari nilai-nilai Islam yang diyakini.
\end{abstract}

Kata kunci: implementasi, monevin, program hibah, Islam 


\section{PENDAHULUAN}

Kualitas Sumber Daya Manusia (SDM) Indonesia sangat jauh jika dibandingkan dengan negara lain. Bersama dengan sejumlah negara ASEAN, kecuali Singapura dan Brunei Darussalam, Indonesia masuk dalam kategori negara yang Indeks Pembangunan Manusia (IPM)-nya di tingkat medium. Jika dilihat dari indikator indeks pendidikan, Indonesia berada di atas Myanmar, Kamboja, dan Laos atau ada di peringkat 6 negara ASEAN. Bahkan indeks pendidikan Vietnam-yang pendapatan perkapitanya lebih rendah dari Indonesia — adalah lebih baik. ${ }^{1}$

Melihat kebutuhan peningkatan kualitas pendidikan, terutama di Perguruan Tinggi, Pemerintah mencanangkan program-program peningkatan kualitas Perguruan Tinggi, salah satunya melalui program hibah. Sumber dana hibah selain berasal dari APBN juga berasal dari dana luar negeri yang berwujud hibah dan pinjaman. Beberapa institusi/lembaga luar negeri yang pernah memberikan pinjaman/hibah antara lain Europian Union, World Bank, IDB (Islamic Development Bank), Pemerintah Belanda dan Pemerintah Amerika Serikat.

Pinjaman dari luar negeri tentu menambah beban negara. Selain harus membayar angsuran utang, Pemerintah juga harus membayar bunga dari utang tersebut. Oleh karena itu, diharapkan dana hibah yang digelontorkan oleh Pemerintah dapat dikelola dengan sebaik-baiknya.

Namun pada kenyataannya, masih terjadi kasus-kasus penyelewangan dana hibah yang dilakukan oleh pihak universitas penerima. Kompas.com (10/03/14) melansir, Pengadilan Tindak Pidana Korupsi Semarang menjatuhkan hukuman 2,5 tahun penjara terhadap

${ }^{1}$ Tim Penyusun, 2010, Panduan Manual Central Project Coordination Unit, Jakarta: Direktorat Jenderal Pendidikan Tinggi-Kementerian Pendidikan Nasional. 
mantan Rektor Universitas Jenderal Soedirman Purwokerto, dalam kasus korupsi dana hibah CSR PT Aneka Tambang yang menyebabkan kerugian negara Rp 2,14 miliar. $^{2}$

Sangat disayangkan, kasus penyelewengan dana hibah tersebut terjadi lingkungan pendidikan yang diharapkan menjadi contoh dalam hal akuntabilitas pengelolaan proyek hibah. Kasus penyelewengan dana yang terjadi di lingkungan Perguruan tinggi seharusnya dapat diantisipasi lebih dini oleh pimpinan dengan mengimplementasikan pengawasan yang efektif.

Pihak-pihak yang terlibat dalam pengelolan dana hibah, perlu meningkatkan pengawasan untuk mengantisipasi penyelewengan dana hibah tersebut. Selain proses audit keuangan yang dilakukan secara insidental oleh BPKP (Badan Pengawas Keuangan dan Pembangunan), pengendalian internal yang baik di universitas dapat meminimalisir dan mencegah penyelewengan dana hibah. Salah satu bentuk pengendalian adalah Monitoring dan Evaluasi.

Berdasarkan data dari Dirjen DIKTI, setelah dilakukan audit oleh BPKP terhadap pelaksanaan hibah PHK PKPD (Program Hibah Kompetisi Peningkatan Pendidikan Dokter), masih banyak temuan penyimpangan yang terjadi. Temuan tersebut adalah kelebihan pembayaran, pekerjaan tidak sesuai ketentuan, penggunaan dana tidak sesuai ketentuan, pertanggungjawaban tidak sesuai ketentuan, denda keterlambatan, sisa dana belum disetor ke Kas Negara, penerimaan negara belum disetor ke Kas Negara dan kesalahan pembebanan. Total temuan pada tahun anggaran 2011-2012 senilai Rp 7.044.836.322, 83.

\section{Tabel}

${ }^{2}$ https://regional.kompas.com/news/regional 
Rekapitulasi Temuan Audit PHK PKPD 2011-2012

\begin{tabular}{|c|c|c|c|c|c|c|c|}
\hline \multirow{2}{*}{ No. } & \multirow{2}{*}{ Kattegoi Temuan } & \multicolumn{2}{|c|}{ Temun } & \multicolumn{2}{|c|}{ Thedklanjyt } & \multicolumn{2}{|c|}{ Salko Teminan } \\
\hline & & Kegatan & Nhi $[$ P P $)$ & Kegatan & Nhi(R) & Kegitan & 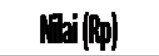 \\
\hline 1 & Kelechihan permbayaran & 75 & $2200.102297,18$ & 67 & $1903,376.42,39$ & 8 & $206.725 .874,79$ \\
\hline 2 & Pekerjann tidak sesua ketentuan & 34 & $1.156272692,80$ & 28 & $266.648923,00$ & 6 & $889.623 .769,80$ \\
\hline 3 & Penggunaan dana tidak sesuai ketenttun & 13 & $430.676 .059,00$ & 11 & $382001.059,00$ & 2 & $47.775 .000,00$ \\
\hline 4 & 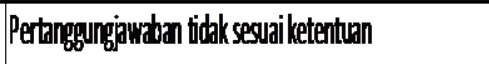 & 8 & $299.614 .550,00$ & 5 & $118.614 .550,00$ & 3 & $181.000,000,00$ \\
\hline 5 & Denta keterlambatan & 19 & 43997965,55 & 17 & $334.155 .49,85$ & 2 & $105.825516,00$ \\
\hline 6 & Sisg dana belum disetor ke Kas Neggra & 4 & $39.191 .055,00$ & 4 & $39.171 .055,00$ & 0 & $20,000,00$ \\
\hline 7 & Penerimann neggra yang belum disetorkan ke Kas Nlegar & 18 & 415.531.162,92 & 17 & 380288315,71 & 1 & $35,242847,21$ \\
\hline 8 & Kesaldhan permbebanan & 41 & $2063.470510,00$ & 34 & $1094.059 .100,00$ & 7 & $969.411 .410,00$ \\
\hline & Junth & 212 & $7,04 ., 85332,83$ & 183 & 4519214904,95 & 29 & $2525.621 .417,8$ \\
\hline
\end{tabular}

Hasil evaluasi akhir yang dilakukan Dirjen DIKTI terhadap kinerja penerima hibah PHK PKPD, Universitas Islam Indonesia dinyatakan sebagai grantee terbaik untuk kategori Perguruan Tinggi Swasta (PTS). Berdasarkan latar belakang di atas, penulis tertarik untuk melakukan penelitian tentang implementasi monitoring dan evaluasi internal pada program hibah studi kasus pada Program Hibah Kompetisi Peningkatan Kualtias Pendidikan Dokter (PHK PKPD) Universitas Islam Indonesia .

\section{TINJAUAN PUSTAKA}

\section{Monevin}

Monitoring dan Evaluasi Internal (monevin) merupakan kegiatan untuk menjamin mutu kegiatan-kegiatan yang dilaksanakan di suatu organisasi/lembaga. Monevin membantu unit-unit pelaksana program 
dalam mengukur tingkat pencapaian tujuan. Unit Monevin merupakan mitra bagi unit pelaksana kegiatan dalam memberikan masukan pada tahap evaluasi program/kegiatan.

Monevin dilakukan mulai pada tahap perencanaan, pelaksanaan, dan akhir kegiatan. Sasaran monevin pada program hibah adalah kegiatan yang dilaksanakan oleh unit-unit yang menerima hibah yang berasal dari sumber luar organisasi. Monevin sering disebut sebagai audit intern.

Audit merupakan suatu proses sistematis untuk memperoleh dan mengevaluasi bukti yang berhubungan dengan asersi tentang tindakan atau kejadian ekonomi secara obyelktif untuk menilai tingkat kepatuhan antara asersi terebut dengan kriteria yang telah ditetapkan serta mengkomunikasikan hasilnya kepada pihak-pihak yang berkepentingan. ${ }^{3}$

Sedangkan Ikatan Auditor Internal mendefenisikan audit internal sebagai berikut :

"Audit intern adalah aktivitas independen, keyakinan obyektif, dan konsultasi yang dirancang untuk menambah nilai dan meningkatkan operasi organisasi. Audit intern ini membantu organisasi mencapai tujuannya dengan melakukan pendekatan sistematis dan disipilin untuk mengevaluasi dan meningkatkan efektifitas manajemen resiko, pengendalian, dan proses tata kelola."4

Dalam buku "Risk and system-Based Internal Auditing" (2005 : 1), Robert Tampubolon berpendapat bahwa :

"fungsi audit intern lebih berfungsi sebagai mata dan telinga manajemen, karena manajemen butuh kepastian bahwa semua

\footnotetext{
${ }^{3}$ Harjono Jusup, 2014, Auditing (Pengauditan Berbasis ISA), Yogyakarta: Penerbit STIE YKPN.

${ }^{4}$ Konsorium Organisasi Profesi Audit Internal, 2004, Standar Profesi Audit Internal, Jakarta.
} 
kebijakan yang telah ditetapkan tidak akan dilaksanakan secara menyimpang".

Meskipun pihak yang melakukan audit intern merupakan bagian dari organisasi yang diaudit itu sendiri, tetapi pelaksanaan audit internal harus tetap obyektif dan independen dari aktivitas yang diaudit. Agar dapat melakukan tugasnya secara efektif, auditor internal harus independen terhadap fungsi-fungsi lini di dalam organisasi tempat ia bekerja.

Untuk memperoleh hasil audit yang baik dan berkualitas pelaksanaan audit harus direncanakan sebaik-baiknya. Audit internal harus menyusun terlebih dulu rencana pemeriksaan yang memadai serta diatur secara sistematis mencakup semua unit yang akan diperiksa, sehingga seluruh pekerjaan dapat dilaksanakan secara berhasil guna dan berdaya guna.

Sedangkan dalam pelaksanaannya, auditor internal melakukan tahap perencanaan audit, pengujian dan pengevaluasian informasi, penyampaian hasil pemeriksaan dan tindak lanjut hasil pemerikasaan.

Hiro Tugiman (2006:75) menyebutkan :

"Tindak lanjut (follow up) oleh audit internal diartikan sebagai suatu proses untuk menentukan kecukupan, keefektifan dan ketepatan waktu dari berbagai tindakan yang dilakukan oleh manajemen terhadap berbagai temuan pemeriksaan yang dilaporkan."

Dari pernyataan di atas dapat diketahui bahwa audit intern harus terusmenerus meninjau atau melakukan tindak lanjut untuk memastikan bahwa terhadap temuan-temuan audit yang dilaporkan telah dilakukan tindakan yang tepat dan tidak berulang untuk hal yang sama. Audit intern harus

\footnotetext{
${ }^{5}$ Robert Tampubolon, 2005, Risk and System-Based Internal Auditing, Jakarta: PT Gramedia

${ }^{6}$ Hiro Tugiman, 2006, Standar Profesional Auditor Internal, Penerbit Kanisius, Jakarta.
} 
memastikan apakah suatu tindakan korektif terhadap berbagai temuan yang dilaporkan telah dilakukan.

\section{Kinerja}

Kinerja merupakan istilah yang berasal dari kata Job Performance atau Actual Performance (pretasi kerja atau prestasi sesungguhnya yang dicapai seseorang). Menurut Mangkunegara kinerja SDM adalah prestasi kerja atau hasil kerja (output) baik kualitas maupun kuantitas yang dicapai SDM persatuan periode waktu dalam melaksanakan tugas kerjanya yang dicapai SDM persatuan periode waktu dalam melaksanakan tugas kerjanya sesuai dengan tanggung jawab yang diberikan kepadanya. ${ }^{7}$

Sinambela (2012) mengemukakan bahwa kinerja pegawai didefinisikan sebagai kemampuan pegawai dalam melakukan sesuatu keahlian tertentu. Kinerja pegawai sangatlah perlu, sebab dengan kinerja ini akan diketahui seberapa jauh kemampuan pegawai dalam melaksanakan tugas yang dibebankan kepadanya. Untuk itu diperlukan penentuan kriteria yang jelas dan terukur serta ditetapkan secara bersama-sama yang dijadikan sebagai acuan. $^{8}$

Dalam bukunya Mangkunegara (2007) menyimpulkan bahwa faktor-faktor penentu prestasi kerja individu dalam organisasi adalah faktor individu dan faktor lingkungan kerja organisasi. Faktor individu dipengaruhi oleh karakter individu yang bersangkutan, sperti kemampuan, pengetahuan, ketrampilan, motivasi, norma dan nilai. Faktor lingkungan organisasi yang dimaksud antara lain uraian jabatan yang jelas autoritas

\footnotetext{
${ }^{7}$ Prabu Mangkunegara, A., 2007, Evaluasi Kinerja SDM, Bandung: Penerbit PT Refika Aditama.

${ }^{8}$ Sinambela Lijan Poltak, 2012, Kinerja Pegawai, Yogyakarta: Grha Ilmu.
} 
yang memadai, target kerja yang menantang, pola komunikasi kerja efektif, hubungan kerja harmonis, iklim kerja respek dan dinamis, peluang berkarir dan fasilitas kerja yang relatif memadai.

Sutikno (2014) mengungkapkan bahwa budaya organisasi yang kuat dapat membantu kinerja karyawan dan kinerja perusahaan, karena akan menciptakan sesuatu yang luar biasa dalam diri karyawan, dan memberikan struktur dan kontrol yang dibutuhkan tanpa harus bersandar pada birokrasi yang formal dan kaku, yang dapat menekan tumbuhnya motivasi dan inovasi karyawan. ${ }^{9}$

Menurut Yahyo (2013), kompensasi juga mempengaruhi kinerja karyawan. Pemberian kompensasi sangat penting bagi perusahaan, karena mencerminkan upaya organisasi untuk mempertahankan sumber daya manusia. Kerugian yang didapat apabila kompensasi diberikan secara tidak tepat adalah perusahaan bisa kehilangan karyawan yang memiliki kinerja yang baik, dan perusahaan harus mengeluarkan biaya lagi untuk penarikan karyawan baru yang berkualitas. ${ }^{10}$

\section{Kerja dalam Pandangan Islam}

Islam sebagai sebuah agama memandang masalah kerja sebagai hal yang penting. Salah satu bagian dari syari'at Islam adalah kewajiban bekerja, dan keharaman berpangku tangan serta bermalas-malasan bagi orang yang berkemampuan untuk bekerja. Allah sangat mencintai seorang muslim yang bekerja keras seperti yang disabdakan oleh Rosulullah,

\footnotetext{
${ }^{9}$ Sutikno, 2014, Pemimpin dan Gaya Kepemimpinan, Edisi Pertama, Lombok: Holistica.

${ }^{10}$ Yahyo, 2013, Pengaruh Motivasi, Lingkungan Kerja dan Kompensasi Terhadap Kinerja Karyawan Melalui Semangat Kerja Karyawan CV Putra Jaya Sahita Guna Semarang, Semarang: Jurnal Universitas Diponegoro.
} 
"Bahwa Allah sangat mencintai orang-orang mukmin yang suka bekerja keras dalam usaha mencari mata pencaharian". (HR. Tabrani dan Bukhari).

Istilah 'kerja' dalam Islam bukanlah semata-mata merujuk kepada mencari rezeki untuk menghidupi diri dan keluarga, tetapi kerja mencakup segala bentuk amalan atau pekerjaan yang mempunyai unsur kebaikan dan keberkahan bagi diri, keluarga dan masyarakat sekelilingnya serta negara. Bekerja adalah manifestasi amal saleh. Bila kerja itu amal saleh, maka kerja adalah ibadah. Dan bila kerja itu ibadah, maka kehidupan manusia tidak bisa dilepaskan dari kerja.

Etos kerja seorang muslim, dibentuk oleh iman yang menjadi pandangan hidupnya, yang memberinya norma-norma dasar untuk membangun dan membina mu'amalahnya. Seorang muslim dituntut oleh imannya untuk menjadi orang yang bertakwa dan bermoral amanah, berilmu, cakap, cerdas, cermat, hemat, rajin, tekun, dan bertekad bekerja sebaik mungkin untuk menghasilkan yang terbaik.

Dalam buku Manajemen Syari'ah dalam Praktik karangan DR. KH. Didin hafidhuddin, M.Sc. dan Hendri Tanjung, S.Si., M.M, ada beberapa ciri etos kerja Islam, antara lain:

1. Al-Shalah atau baik dan manfaat.

"Barang siapa yang mengerjakan amal saleh, baik laki-laki maupun perempuan dalam keadaan beriman, maka sesungguhnya akan kami berikan kepadanya kehidupan yang baik dan sesungguhnya dan sesungguhnya akan kami beri balasan kepada mereka dengan pahala yang lebih baik dari apa yang telah mereka kerjakan."(an-Nahl:97)

2. Al-Itqan atau kemantapan dan perfectnees 
"Sesungguhnya Allah sangat mencintai jika seseorang melakukan suatu pekerjaan yang dilakukannya dengan itqan/sempurna (professional)." (HR Thabrani)

3. Al-Ihsan atau melakukan yang terbaik dan lebih baik lagi "Allah yang menjadikan mati dan hidup supaya dia menguji kamu, siapa diantara kamu yang paling baik amalnya." (Qs Al Mulk: 2)

4. Al-Mujahadah atau kerja keras yang optimal

"Dan orang-orang yang berjihad untuk (mencari keridhaan) kami, benar-benar akan kami tunjukkan kepada mereka jalan-jalan kami. Dan sesungguhnya Allah benar-benar beserta orang-orang yang berbuat baik." (Qs Al-Ankabuut: 69)

"Apabila kamu telah selesai dari suatu urusan, maka kerjakanlah dengan sungguh-sungguh urusan yang lain." (Qs Al Insyiroh: 7)

5. Tanafus dan ta'awun atau berkompetisi dan tolong menolong Dan tolong menolonglah kamu dalam (mengerjakan) kebajikan dan takwa dan jangan tolong-menolong dalam berbuat dosa dan pelanggaran. Dan bertakwalah kamu kepada Allah, sesungguhnya Allah amat berat siksanya." (Al-Maa'idah: 2)

6. Mencermati nilai waktu

"Siapkan lima sebelum (datangnya) lima. Masa hidupmu sebelum datang waktu matimu, masa sehatmu sebelum datang waktu sakitmu, masa senggangmu sebelum datang masa sibukmu, masa mudamu sebelum datang masa tuaтu, dan masa kayamu sebelum datang masa miskinmu." (HR Baihaqi dari Ibnu Abbas). ${ }^{11}$

\footnotetext{
${ }^{11}$ KH Didin Hafidhudin dan Hendri Tanjung, 2003, Manajemen Syariah dalam Praktek, Jakarta: Gema Insani
} 


\section{KERANGKA PEMIKIRAN}

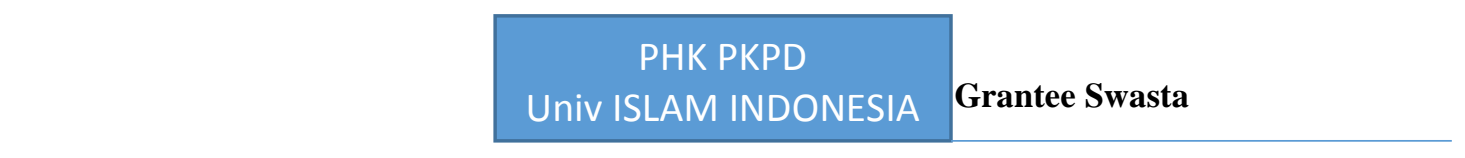

Monitorir.g dan

Evaluasi Internal

(MONEVIN)

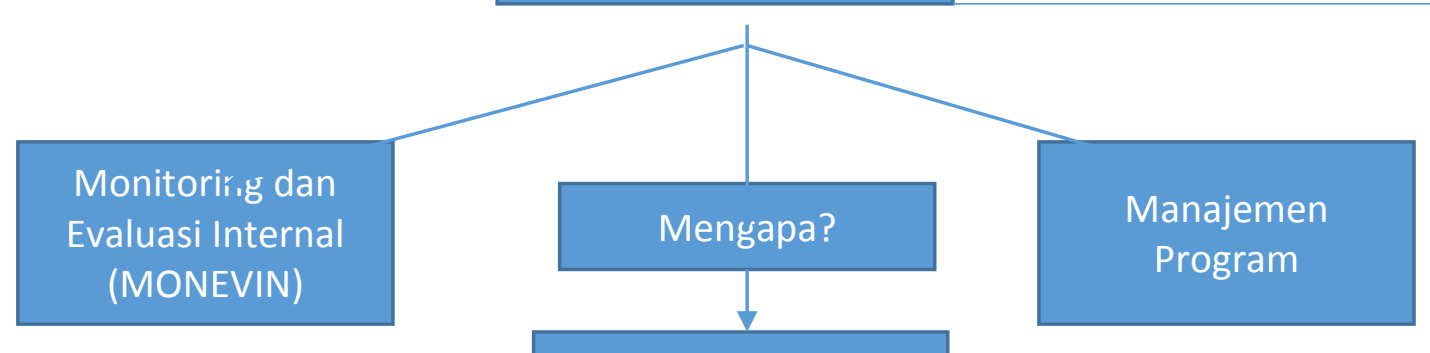

Pengumpulan Data

sebagai grantee (penerima_......., Penelitian …... ori Perguruan Tinggi

Analisis Data

Swasta/BHMN (Badan Hukum Milik Negara). Dalam penilaian Dirjen

Dikti. Universitas Islam Indonesia berhasil memperoleh score tertinggi dalam pelaksanaan program hibah tersebut mengalahkan puluhan universitas ternama, baik universitas swasta yang berbasis keagamaan maupun universitas BHMN seperti Universitas Gadjah Mada.

Penulis ingin mengetahui implementasi Monevin (Monitoring dan Evaluasi Internal) Program Hibah dalam pencapaian prestasi PHK PKPD Universitas Islam Indonesia, dan hal-hal lain apakah yang ikut mendukung pencapaian tersebut. Untuk mendapatkan kesimpulan yang lebih mendalam, penulis melakukan penelitian pada PHK PKPD Universitas Islam Indonesia sehingga diperoleh data-data yang akurat melalui 
observasi dan wawancara kepada pihak-pihak yang terlibat dalam program hibah tersebut.

\section{METODOLOGI PENELITIAN}

\section{Desain Penelitian}

Penelitian ini menggunakan metode kualitatif dengan desain penelitian studi kasus tunggal. Studi kasus tunggal pada umumnya hanya melibatkan satu lingkungan tertentu dan pada periode tertentu pula. Satu lingkungan dipilih karena dianggap memiliki keunikan yang tidak dimiliki oleh lingkungan lain. Dengan demikian, studi kasus tunggal tidak dimaksudkan untuk membuat kesimpulan yang akan diterapkan pada kasus lain. $^{12}$

\section{Data dan Sumber Data}

Data yang digunakan dalam penelitian ini adalah data primer. Sedangkan sumber data yang digunakan pada penelitian ini adalah:

1. Dokumen

Dokumen yang dijadikan data dalam penelitian ini antara lain: panduan manual proyek, proposal PHK PKPD Universitas Islam Indonesia, Rencana Implementasi Proyek (RIP) dan Laporan Akhir PHK PKPD Universitas Islam Indonesia.

2. Rekaman arsip

Rekaman arsip yang digunakan dalam penelitian ini antara lain: daftar hadir pertemuan manajemen program dan tim monevin, bagan struktur organisasi, notulensi pertemuan manajemen program dan tim monevin, program kerja tim monevin.

${ }^{12}$ Yin, R. K, 2011, Studi Kasus, Desain dan Metodologi. Jakarta: Raja Grafindo Persada. 
3. Wawancara

Tipe wawancara yang digunakan adalah open ended, dimana peneliti bertanya kepada narasumber yang merupakan pihak-pihak yang bersangkutan dengan program.

\section{Observasi Partisipan}

Observasi partisipan adalah bentuk observasi khusus dimana peneliti tidak hanya menjadi pengamat pasif melainkan juga berperan dalam situasi tertentu dan berpartisipasi dalam peristiwa/kasus yang akan diteliti.

\section{Pengujian Validitas dan Reabilitas Data}

Data yang valid dapat diperoleh dengan melakukan uji kredibilitas. Adapun macam-macam pengujian kredibilitas menurut Sugiyono (2014) antara lain dilakukan dengan perpanjangan pengamatan, peningkatan ketekunan dalam penelitian, triangulasi, diskusi dengan teman sejawat, analisis kasus negatif, dan membercheck. ${ }^{13}$

Penelitian ini menggunakan metode pengujian kredibilitas dengan cara perpanjangan pengamatan, triangulasi dan memberchek. Perpanjangan pengamatan telah dilakukan peneliti dengan menjadi staf proyek PHK PKPD Universitas Islam Indonesia tahun 2011-2014. Triangulasi sumber dilakukan dengan melakukan wawancara dengan berbagai sumber. Peneliti juga melakukan pengecekan data kepada para narasumber (membercheck).

\section{Analisis Data}

Analisis data kualitatif adalah upaya yang dilakukan dengan jalan bekerja dengan data, mengorganisasikan data, memilah-milahnya menjadi

${ }^{13}$ Sugiyono, 2014, Metode Penelitian Pendidikan Pendekatan Kuantitafif, Kualitati dan $R \& D$, Bandung: Alfabeta. 
satuan yang dapat dikelola, mensintesiskannya, mancari dan menemukan pola, menemukan apa yang penting dan apa yang dipelajari, dan memustuskan apa yang dapat diceritakan kepada orang lain. Mengacu pada pendapat Miles dan Huberman, proses penelitian ini berbentuk siklus meliputi pengumpulan data, display data, reduksi data, dan penarikan kesimpulan $^{14}$

\section{HASIL DAN PEMBAHASAN}

\section{Profil Institusi}

Universitas Islam Indonesia didirikan pada tanggal 27 Rajab 1364 $\mathrm{H}$ atau bertepatan dengan 8 Juli 1945, dengan nama Sekolah Tinggi Islam (STI) di Jakarta. Dibidani oleh tokoh-tokoh nasional seperti Dr. Moh. Hatta (Proklamator dan mantan Wakil Presiden RI), Moh. Natsir, Prof. KHA. Muzakkir, Moh. Roem, KH. Wachid Hasyim, dll, menjadikan STI sebagai basis pengembangan pendidikan yang bercorak nasional dan Islamis serta menjadi tumpuan harapan seluruh anak bangsa.

Seiring hijrahnya ibukota Republik Indonesia ke Yogyakarta, maka STI pun hijrah dan diresmikan kembali oleh Presiden Soekarno pada tanggal 10 April 1946 bertempat di nDalem Pangulon Yogyakarta. Untuk

\footnotetext{
${ }^{14}$ Miles, M.B, Huberman,A.M, dan Saldana,J. 2014, Qualitative Data Analysis, A. Methods Sourcebook Edition 3.
} 
peningkatan peran dalam perjuangan, maka STI yang kala itu menjadi satu-satunya perguruan tinggi Islam, diubah menjadi universitas dengan nama University Islam Indonesia atau sekarang Universitas Islam Indonesia pada tahun 1947.

Realisasi perubahan STI menjadi UII didahului pembukaan kelas pendahuluan (semacam pra universitas) yang diresmikan pada bulan Maret 1948 di Pendopo nDalem Purbojo, Ngasem Yogyakarta. Sedangkan pembukaan UII (menggantikan STI) secara resmi diselenggarakan pada tanggal 27 Rajab 1367 H (bertepatan dengan tanggal 4 Juni 1948) bertempat di nDalem Kepatihan Yogyakarta dan mendapat kunjungan dari para menteri serta pejabat sipil dan militer lainnya.

Satu misi sederhana dalam kata namun berat, sangat berat, bahkan dalam kenyataannya yang teremban dalam perjalanan sejarah ini adalah mewujudkan kata-kata Bung Hatta dalam pidato peresmian UII kala itu “...di Sekolah Tinggi Islam ini akan bertemu agama (religion) dengan ilmu (science) dalam kerjasama yang baik untuk membantu peningkatan kesejahteraan masyarakat... "15

\section{Struktur Organisasi}

Penanggung jawab program adalah Rektor Universitas Islam Indonesia. Ketua Pelaksana Program adalah Dekan Fakultas Kedokteran Universitas Islam Indonesia. Koordinator Administratif Keuangan dijabat langsung oleh Wakil Dekan.

Direktur Eksekutif membawahi oleh Koordinator Program, Koordinator Pengadaan Barang dan Jasa serta Koordinator Administrasi dan Keuangan, serta beberapa staf pendukung. Koordinator Program

\footnotetext{
${ }^{15}$ www.uii.ac.id
} 
dibantu oleh lima koordinator lain, sedangkan Koordinator Pengadaan Barang dan Jasa, dan Koordinator Administrasi Keuangan memiliki staf untuk mengelola kegiatannya.

Monevin (Monitoring dan Evaluasi Internal) PHK-PKPD Universitas Islam Indonesia dilaksanakan oleh sebuah tim yang dibentuk oleh Rektor. Monevin beranggotakan personal BPM (Badan Penjamin Mutu) tingkat universitas yang berfungsi untuk mengelola, mengevaluasi, memonitor dan mengawal kinerja lembaga pendidikan tinggi secara sistematis.

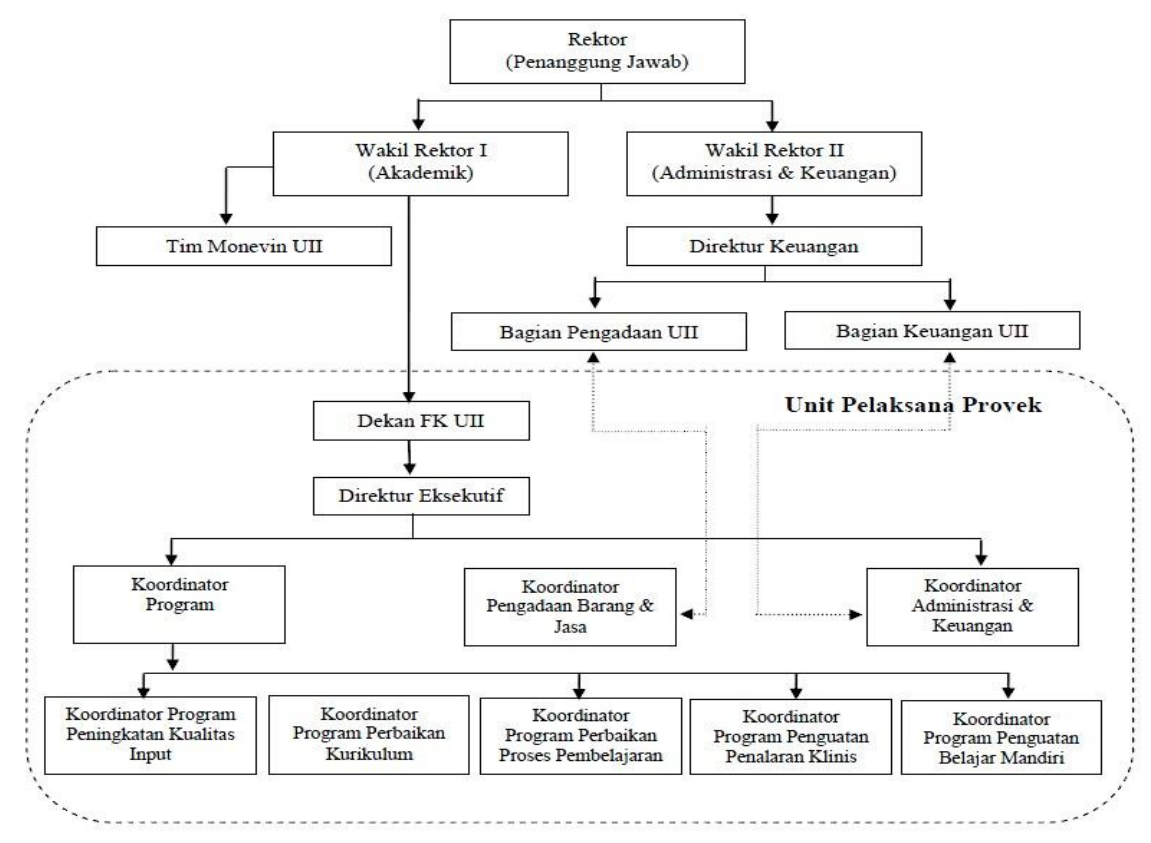

Gambar Struktur Manajemen PKPD UII

\section{Deskripsi Narasumber}

Narasumber berasal dari pihak Tim Monevin, Ketua Pelaksana (Dekan Fakultas), Direktur Eksekutif dan Staf Akuntansi.

\section{Hasil Pengumpulan Data}


Data-data yang didapatkan oleh penulis adalah Profil Institusi, Program Kerja Tim Monevin, Berita Acara Audit BPKP, Tindak Lanjut Temuan, Struktur Organisasi dan Laporan Akhir Proyek.

\section{Pembahasan dan Analisis Data}

Program Kerja Monevin PHK PKPD Universitas Islam Indonesia

Program Kerja Tim Monevin merupakan program kerja keseluruhan dalam lingkup Monevin. Tidak ada program kerja khusus yang disusun oleh Tim Monevin Keuangan PHK PKPD Universitas Islam Indonesia.

Adapun program kerja Tim Monevin adalah pembentukan tim, penyusunan rencana kerja, workshop tim monevin, penyamaan persepsi tim monevin dan pengelola program, monev awal, monev periodik, monev tengah dan monev akhir.

Implementasi Program Kerja Monevin PHK PKPD Universitas Islam Indonesia

Narasumber 1 menerangkan,

"Kita sering terlewat program kerjanya, jadi digabung-gabung realisasinya. Harusnya monev-nya kan per triwulan tapi seringnya digabung. Kemarin kita terlambat juga penyusunan Tim Monevinnya. Jadi program sudah jalan kita belum bekerja, karena ada pergantian struktural."

Dari penulusuran dokumen Daftar Hadir Rapat Koordinasi Tim Monevin diperoleh data realisasi program kerja sbb: Koordinasi Awal dan Rencana Kerja Tim, Persiapan Visitasi Monev Eksternal PHK PKPD dan Pendampingan Visitasi Monev Eksternal PHK PKPD 
Setelah dilakukan wawancara dan penulusuran dokumen, diperoleh data bahwa kegiatan Monevin di PHK PKPD Universitas Islam Indonesia terlaksana 4 kali. Program Kerja Monevin PHK PKPD Universitas Islam Indonesia yang terlaksana yaitu Penyusunan Rencana Kerja dan Pendampingan Monev Eksternal. Program Kerja yang lain tidak terlaksana.

Efektivitas Implementasi Monevin PIU PHK PKPD Universitas Islam Indonesia

Narasumber ketiga pada Universitas Islam Indonesia mengatakan, "Monev di awal-awal proyek masih kita rasakan pendampingannya. Namun mulai tahun kedua dan seterusnya, pendampingan sudah menurun intensitasnya, bahkan tidak terasa pendampingannya."

Dari uraian narasumber tersebut, dapat disimpulkan bahwa implementasi Monevin di PHK PKPD Universitas Islam Indonesia kurang efektif karena kurangnya pendampingan terhadap Manajemen Program.

\section{Aspek-Aspek Pendukung Kinerja Monevin}

Berdasarkan wawancara dan hasil observasi peneliti, ada beberapa aspek penting yang mendukung kinerja Tim Monevin. Beberapa aspek yang disampaikan informan adalah sbb:

1. Kompensasi (Imbalan Kerja)

Tim Monevin PHK PKPD merupakan staf pengajar (dosen) di universitas, sehingga Tim Monevin telah mendapatkan gaji pokok sebagai staf pengajar. Honorarium yang diberikan kepada Tim Monevin merupakan 
kompensasi tambahan atas tugas yang diberikan universitas terkait Tim Monevin hibah.

Tidak ada ketentutan baku dari CPCU Dikti yang mengatur besarnya honorarium Tim Monevin. Manajemen program hibah diberikan kebebasan menentukan besarnya honorarium Tim Monevin dengan mempertimbangkan kebijakan internal yang berlaku di universitas.

Honorarium Tim Monevin berasal dari DRK (Dana Rekening Khusus) Komitmen yaitu dana pendamping yang bersumber dari universitas sebagai bentuk komitmen untuk mendukung keberlangsungan program hibah. Universitas dihimbau untuk menyediakan DRK Komitmen minimal 10\% dari total dana hibah yang diterima dari pemerintah.

Manajemen Program PHK PKPD Universitas Islam Indonesia memberikan honorarium kepada Tim Monevin dalam dua termin, yaitu pertengahan tahun dan akhir tahun. Menanggapi besarnya honorarium Tim Monevin, narasumber 2 di PHK PKPD Universitas Islam Indonesia mengatakan: "Hmm..saya rasa kurang ya honornya, perlu dinaikkan."

Seperti yang dikatakan Narasumber 2, Narasumber 4 pun merasa honorarium yang diterima Tim Monevin kurang sesuai dengan tanggung jawabnya: "Kalau mereka bekerja sesuai jobnya, kurang honor segitu."

Peneliti mencari perbandingan data honorarium ke penerima hibah universitas lain dan mendapatkan informasi bahwa honorarium yang diperoleh setiap orang Tim Monevin di universitas tersebut 6.25 kali lebih besar daripada honorarium tiap orang di Monevin pada PHK PKPD universitas Islam Indonesia.

Ninuk Muljani mengemukakan, karyawan akan merasa puas dan meningkatkan kinerjanya jika kompensasi yang diberikan sesuai dengan 
keadilan. Tanggung jawab monevin cukup berat untuk mengontrol dan mendampingi program hibah. Kompensasi yang diberikan Universitas Islam Indonesia menurut narasumber kurang sesua dengan beratnya tanggung jawab Monevin. ${ }^{16}$

\section{Kompetensi}

CPCU Dikti memberikan pedoman kualifikasi personal Tim Monevin yang tertuang dalam Project Managemen Manual Health Professional Education Quality Project (HPEQ). Adapun kualifikasi kompetensi tersebut adalah:

- Mempunyai pendidikan minimal D3, terutama dalam bidang manejemen/perencanaan

- Berpengalaman dalam proyek-proyek dengan proyek-proyek pemerintah sebagai staf monitoring dan evaluasi atau konsultan.

Kualifikasi yang ditetapkan oleh CPCU Dikti diharapkan menjadi acuan bagi manejemen program untuk menyeleksi kompetensi personal yang akan ditunjuk sebagai Tim Monevin.

Tim Monitoring PHK PKPD Universitas Islam Indonesia yang berjumlah 10 (sepuluh) orang memiliki keahlian masing-masing. Pada awalnya, formasi keahlian Tim Monevin cukup ideal untuk mendampingi proyek hibah. Ada staf monevin yang ahli dalam bidang pengadaan barang dan jasa, keuangan dan program akademik. Namun seiring

\footnotetext{
${ }^{16}$ Muljani, Ninuk. 2002. Kompensasi Sebagai Motivator Untuk Meningkatkan Kinerja Karyawan, Jurnal Manajemen dan Kewirausahaan Vol. 4 No. 2, September 2002, 108122.
} 
perjalanan proyek, terjadi beberapa kali pergantian personal, termasuk Staf Monevin Keuangan.

Ada dua orang staf Monevin Keuangan. Semuanya merupakan staf edukatif (dosen) yang masih memiliki tanggung jawab akademik di universitas. Karena kesibukan salah seorang staf Monevin Keuangan, hanya satu orang staf Monevin yang terlibat di proyek. Satu staf Monevin Keuangan tersebut tidak memiliki latar belakang pendidikan akuntansi ataupun ekonomi seperti yang dituturkan narasumber 1:

"Saya orang tehnik, nggak faham betul pembukuan, alur keuangan proyek juga. Dulu ada workshop Monevin dari DIKTI, tapi nggak ada yang khusus keuangan. Saya juga nggak diikutkan waktu itu. Cuma sekali seumur proyek workshopnya."

Padahal latar belakang pendidikan akuntansi sangat diperlukan untuk menunjang kompetensi Monevin Keuangan. Narasumber 4 menyampaikan bahwa Monevin Keuangan tidak memahami keuangan proyek:

"Saya rasa kok Monevin tidak terlalu paham tentang keuangan proyek ya. Kayaknya kan bukan orang akuntasi. Pembukuan saya cuma dicek sekali. Laporan IFR juga tidak dicek."

Narasumber 3 mengatakan:

"Setahu saya memang di UII monevin keuangan tidak harus punya background akuntansi, yang penting pernah punya pengalaman di proyek-proyek sebelumnya. Saya tidak tahu mereka ada workshop khusus keuangan atau tidak."

Monevin Keuangan PHK PKPD Universitas Islam Indonesia berlatar belakang pendidikan tehnik. Hal ini tentu menjadi hambatan dalam memahami pembukuan akuntansi dan alur keuangan. Apalagi untuk memahami pembukuan, laporan keuangan dan alur keuangan proyek yang 
cukup rumit dan lebih spesifik dibandingkan pembukuan, laporan keuangan \& alur keuangan pada umumnya.

Kompetensi Tim Monevin dapat ditingkatkan melalui workshop/pelatihan. Akan tetapi Universitas Islam Indonesia tidak menyelenggarakan workshop untuk Monevin. Monevin hanya mengikuti satu kali workshop yang diselenggarakan oleh CPCU. Tidak semua tim monevin mengikuti workshop tersebut. Tanpa latar belakang pendidikan akuntansi dan workshop keuangan yang rutin, monevin keuangan PHK PKPD Universitas Islam Indonesia mengalami kesulitan untuk menjalankan fungsinya.

\section{Budaya Organisasi}

Islam mengajarkan pemeluknya untuk bersungguh-sungguh dalam bekerja. Kesungguhan, kerja keras, totalitas, amanah, jujur dan nilai-nilai kebaikan lain yang diajarkan Islam dalam bekerja tidak hanya sekedar untuk mendapatkan prestasi kerja dunia, tapi juga dalam rangka beribadah kepada Allah.

Universitas Islam Indonesia yang memiliki visi menjadi rohmatan lil 'alamin, berupaya menumbuhkan budaya organisasi yang sesuai dengan nilai-nilai Islam. Namun dalam implementasinya, para narasumber menuturkan bahwa nilai-nilai Islam belum menjadi budaya organisasi di kalangan pegawai.

Narasumber 2 mengatakan:

"Islam menekankan bahwa setiap amalan itu bisa bernilai ibadah, tergantung naitnya. Di UII, setiap pegawai diharapkan memiliki etos kerja yang baik, dengan menekankan pada nilai-nilai keislaman, jujur, amanah, loyalitas, bersungguh-sungguh dan semacamnya. Untuk dosen dan pegawai tetap, setahu saya selalu 
ada orientasi atau semacam penataran untuk pegawai baru, termasuk mengkaji ayat-ayat Al Qur'an. Yang kemarin-kemarin sih beberapa pegawai masih belum bisa mempraktekkan etos kerja yang baik tsb, misal masih terlambat atau diberi amanah tidak bisa selesai tepat waktu."

Orientasi bekerja untuk ibadah juga belum tercermin dari kinerja pegawai. Sebagian besar pegawai masih beroerientasi materi saja dengan mengejar tambahan honorarium dari Surat Tugas yang didapatkan. Disampaikan oleh Narasumber 1: "Ya sering memang ST numpuk di satu orang. Ya memang karena orang itu yang kompeten, jadi beban kerjanya banyak."

Tambahan honorarium dari Surat Tugas yang didapatkan oleh pegawai di Universitas Islam Indonesia, dipicu dengan pemberian kompensasi yang kurang proporsionalnya cenderung mengakitbatkan para pegawai berlomba untuk mendapatkan Surat Tugas sebanyak mungkin. Seperti yang dituturkan narasumber, seringkali ST menumpuk di satu pegawai. Sehingga para pegawai tidak fokus mengerjakan salah satu tugas karena banyaknya tugas-tugas lain yang diberikan.

Universitas Islam Indonesia telah berupaya menanamkan nilainilai keagamaan pada para pegawai. Namun, nilai-nilai Islam yang mengajarkan kejujuran, loyalitas, bersungguh-sungguh dan amanah, baru menjadi wacana di kalangan para pegawai dan belum bisa menjadi budaya kerja.

Temuan Audit Keuangan pada PIU PHK PKPD Universitas Islam Indonesia dan Peran Monevin Keuangan dalam Menindaklanjuti Temuan Tersebut 
Pada Tahun Anggaran 2013, tidak terdapat temuan audit pada PHK PKPD Universitas Islam Indonesia. Tidak adanya temuan audit, menurut para narasumber karena loyalitas dan kinerja manejemen program yang sangat baik. Narasumber pertama mengatakan:

"Direkturnya gesit banget, kinerja timnya juga sangat bagus." Penuturan narasumber ketiga juga menguatkan pernyataan narasumber pertama,

"Menurut saya karena loyalitas teman-teman PIU bagus, integritasnya kuat, jadi tidak ada temuan audit."

$\underline{\text { Peran Monevin dalam Menindaklanjuti Temuan Audit }}$

Dari keterangan narasumber kedua, peneliti mendapatkan informasi bahwa temuan audit pada tahun anggaran 2012, dalam catatan BPKP belum ditindaklanjuti hingga tanggal 27 Maret 2014. Seperti yang dituturkan oleh Narasumber 3:

"Tidak ada pendampingan Monevin dalam menindaklanjuti temuan-temuan audit. Sehingga kita telat melaporkan tindak lanjut penyelesaian temuan audit tahun anggaran 2012.”

Pada tindak lanjut temuan audit BPKP, Monevin PHK PKPD Universitas Islam Indonesia hanya sebatas memberikan masukan dan saran, tindak lanjutnya diserahkan sepenuhnya ke manajemen program. Tidak ada monitoring dari Monevin atas tindak lanjut tersebut. Sehingga monevin juga tidak mengetahui bahwa ada temuan audit BPKP Tahun Anggaran 2012 yang tindak lanjutnya belum dilaporkan sampai dengan tahun 2014 sehingga BPKP masih mencatat sebagai temuan yang belum ditindaklanjuti. 


\section{Analisis Data}

Secara garis besar program kerja Tim Monevin PHK PKPD adalah: Pembentukan Tim Monev, Penyusunan Rencana Kerja, Workshop Tim Monev, Penyamaan Persepesi Tim Monev dan Pengelola Program, Monev Awal Tahun, Monev Periodik, Monev Tengah Tahun, dan Monev Akhir Tahun.

Dalam audit BPKP Tahun Anggaran 2013, tidak ada temuan audit pada PHK PKPD Universitas Islam Indonesi, namun terjadi keterlambatan pelaporan tindak lanjut temuan audit tahun sebelumnya. Monevin PHK PKPD Universitas Islam Indonesi sebatas memberikan masukan untuk menindaklanjuti temuan audit, tidak melakukan pendampingan hingga proses pelaporan tindak lanjut temuan.

Beberapa aspek yang menguatkan kinerja Tim Monevin antara lain: kompensasi, kompetensi dan budaya organisasi. Berdasarkan informasi narasumber, kompensasi yang diberikan kepada Tim Monevin masih rendah dibandingkan dengan universitas lain. Kompetensi Tim Monevin juga masih perlu ditingkatkan. Budaya organisasi belum mencerminkan etos kerja Islami yang mengajarkan nilai-nilai kedisplinan, kejujuran, keikhlasan dan loyalitas.

Pendampingan Monevin di PHK PKPD Universitas Islam Indonesia belum berjalan efektif, tapi karena kinerja dan loyalitas manejemen program baik, tidak ada temuan audit BPKP pada pelaksanaan PHK PKPD Universitas Islam Indonesia.

\section{KESIMPULAN DAN SARAN}

\section{Kesimpulan}

Dari hasil analisi data, penulis menarik kesimpulan sebagai berikut: 
1. Implementasi program kerja Monevin baik di PHK PKPD Universitas Islam Indonesia belum terlaksana secara efektif. Pendampingan Tim Monevin di PHK PKPD Universitas Islam Indonesia juga tidak berjalan intensif. Audit monevin baru terlaksana 2 kali.

2. Beberapa aspek yang mendukung kinerja Monevin antar lain: kompensasi, kompetensi dan budaya organisasi.

3. Tim Monevin PHK PKPD Universitas Islam Indonesia tidak melakukan pendampingan dan pengawasan terhadap tindak lanjut audit BPKP sehingga terjadi keterlambatan pelaporan tindak lanjut temuan audit BPKP pada tahun anggaran 2012.

4. Meskipun implementasi Monevin belum berjalan dengan baik, akan tetapi kinerja Manajemen Program sangat baik, sehingga memperoleh prestasi sebagai grantee terbaik untuk kategori Perguruan Tinggi Swasta/Badan Hukum Milik Negara (BHMN).

\section{Saran}

Universitas Islam Indonesia hendaknya memperbaikim sistem audit internal/monevin baik dari sisi pemberian kompensasi, penempatan pegawai pada struktur monevin yang sesuai dengan kompetensinya dan melakukan pembinaan keagamaan secara berkesinambungan sehingga nilai-nilai Islam dapat menjadi budaya kerja.

\section{Keterbatasan Penelitian}

Penelitian ini memiliki beberapa keterbatasan yang mungkin mempengaruhi hasil penelitian yang dicapai. Keterbatasan-keterbatasan tersebut adalah: 
1. Penelitian dibatasi pada implementasi Monevin Keuangan atau yang berdampak pada temuan audit BPKP sehingga implementasi pada bagian selain keuangan tidak menjadi fokus penelitian.

2. Terbatasnya narasumber karena padatnya kegiatan para pegawai yang akan diwawancarai.

3. Hasil penelitian ini hanya menganalisa objek penelitian yang terbatas pada PHK PKPD Universitas Islam Indonesia. Bila penelitian dilakukan pada Perguruan Tinggi penerima hibah yang lain dapat dimungkinkan terjadi perbedaan hasil dan kesimpulan.

\section{DAFTAR PUSTAKA}

Central Project Coordination Unit (CPCU). (2010). Project Management Manual Healt Professional Education Quality. Jakarta: Direktorat Jenderal Pendidikan Tinggi-Kementerian Pendidikan Nasional.

Hafidhuddin, dkk. (2003). Manajemen Syari'ah Dalam Praktik cet ke-1. Jakarta: Gema Insani Press.

Hiro, Tugiman. (2006). Standar Profesional Auditor Internal. Jakarta: Kanisius.

https://regional.kompas.com/news/regional.

Mangkunegara, A. Prabu. (2007). Evaluasi Kinerja SDM. Bandung: PT.RefikaAditama

Miles, M.B, Huberman,A.M, dan Saldana,J. 2014, Qualitative Data Analysis, A. Methods Sourcebook Edition 3 
Muljani, Ninuk. 2002. Kompensasi Sebagai Motivator Untuk Meningkatkan Kinerja Karyawan, Jurnal Manajemen dan Kewirausahaan Vol. 4 No. 2, September 2002, 108-122.

Prabu Mangkunegara, A., 2007, Evaluasi Kinerja SDM, Bandung: Penerbit PT Refika Aditama.

Sinambela Lijan Poltak, 2012, Kinerja Pegawai, Yogyakarta: Grha Ilmu.

Sugiyono, 2014, Metode Penelitian Pendidikan Pendekatan Kuantitafif, Kualitati dan $R \& D$, Bandung: Alfabeta.

Sutikno, 2014, Pemimpin dan Gaya Kepemimpinan, Edisi Pertama, Lombok: Holistica.

www.uii.ac.id

Yahyo. (2013). Pengaruh Motivasi, Lingkungan Kerja, dan Kompensasi Terhadap Kinerja Karyawan Melalui Semangat Kerja Karyawan CV. Putra Jaya Sahita guna, Semarang. Diponegoro Journal of Social and Politic. Universitas Diponegoro.

Yin, R. K. (2002). Studi Kasus, Desain \& Metodologi. Jakarta: Raja Grafindo Persada. 